\title{
ARTIGOS
}

\section{AMERICAN CUTANEOUS LEISHMANIASIS: PRESENTATION AND PROBLEMS OF PATIENT MANAGEMENT}

\section{Jeffrey D. Chulay, Charles N. Oster, Patrick B. McGreevy, Larry D. Hendricks and Richard D. Kreutzer}

\begin{abstract}
We report our experience with the diagnosis and treatment of 60 patients with American cutaneous leishmaniasis. They were infected in Panama (55), Brazil (4) or Colombia (1). Among 35 patients with a 3 week exposure in Panama, the mean maximum incubation period was 33 days (range 4-81 days). Diagnosis was delayed an average of 93 days after onset of skin lesions, due to the patient's delay in seeking medical attention ( 31 days), medical personnel's delay in considering the diagnosis (45 days), and the laboratory's delay in confirming the diagnosis ( 17 days). Forty-four patients ( $73 \%$ ) developed ulcers typical of cutaneous leishmaniasis. Sixteen additional patients $(27 \%)$ had atypical macular, papular, squamous, verrucous or acneiform skin lesions that were diagnosed only because leishmanial cultures were obtained. Of the 59 patients treated with pentavalent antimonial drugs, only 34 (58\%) were cured after the first course of treatment. Lesions which were at least $2 \mathrm{~cm}$ in diameter, ulcerated, or caused by Leishmania braziliensis were less likely to be cured after a single course of treatment than were lesions smaller than $2 \mathrm{~cm}$, nonulcerated or caused by Leishmania mexicana or Leishmania donovani
\end{abstract}

Key words: American cutaneous leishmaniasis. Diagnosis. Treatment. Prognosis. Clinical Pathology.

Leishmaniasis is a group of diseases caused by parasitic protozoa of the genus Leishmania. Different species of Leishmania cause different disease syndromes. Visceral leishmaniasis is caused by infection with Leishmania donovani. Cutaneous leishmaniasis in the Old World is caused by Leishmania tropica, Leishmania major or Leishmania aethiopica, while in the New World it is caused by Leishmania mexicana or Leishmania braziliensis. L. braziliensis can also cause mucosal disease.

Between 1977 and 1982, 60 patients with American cutaneous leishmaniasis were treated at the Walter Reed Army Medical Center. The management of these patients was often difficult because: 1) many presented with atypical lesions; 2) confirmation of the diagnosis often required several weeks; and 3 ) only $58 \%$ of patients were cured after a single 10 day course of treatment with pentavalent antimonial drugs. We report here our experience with these 60 patients.

Walter Reed Army Institute of Research, Washington, DC 20307-5100 and Youngstown State University, Youngstown, OH 44555 USA.

Address correspondence to Dr. Chulay, Department of Immunology, Walter Reed Amy Institute of Research. Washington, DC 20307-5100.

Recebido para publicaçào em 9/9/88.

\section{MATERIALS AND METHODS}

We obtained a general medical history, a detailed travel history, and a complete physical examination on each patient. Serum was examined for antibodies to Leishmania by the direct agglutination test (one patient) performed at the Centers for Disease Control, Atlanta, $\mathrm{GA}^{1}$, or by the indirect fluorescent antibody (IFA) test (44 patients) performed at the Walter Reed Army Institute of Research ${ }^{23}$. Tissue was aspirated from all cutaneous lesions and cultured at $24 \mathrm{C}$ in Schneider's Drosophila Medium with $30 \%$ fetal bovine serum ${ }^{13}$. Skin biopsies performed on 31 patients were examined histologically and cultured for Leishmania, bacteria, fungi and mycobacteria. Leishmanial isolates which grew sufficiently in culture were speciated by isoenzyme analysis 1617 . In brief, lysates of promastigotes were electrophoresed on cellulose acetate to separate enzymes into discrete bands which were visualized by staining for specific enzyme activity. Species identification was made by comparing the isoenzyme profiles of the patient isolates with profiles from World Health Organization reference strains run in parallel.

Most patients were treated with sodium stibogluconate according to the manufacturer's recommendations ( 10 patients $)^{8}$ or under an Investigational New Drug Protocol of the Walter Reed Army Institute of 
Chulay JD, Oster CN, McGreevy PB, Hendricks LD, Kreutzer RD. American cutaneous leishmaniasis: presentation and problems of patient management. Revista da Sociedade Brasileira de Medicina Tropical 21: 165-172, Out-Dez, 1988

Research (45 patients) ${ }^{22}$. The drug was given at a dose of $10 \mathrm{mg}$ antimony $(\mathrm{Sb}) / \mathrm{kg}$ body weight/day (maximum $600 \mathrm{mg} \mathrm{Sb} / \mathrm{d}$ ) for 10 day. Patients who were not cured were given additional 10 day courses at this same dose. Three patients were treated with meglumine antimoniate, $850 \mathrm{mg} \mathrm{Sb} /$ day for 20 day, as initial therapy. Three patients were treated with amphotericin B, and one patient with trimethoprim-sulfamethoxazole, after failure of antimony therapy.

All patients were examined daily for signs of response to therapy and questioned about the occurrence of symptoms related to therapy. Before, during, and after each treatment course, the following laboratory tests were performed: serum $\mathrm{Na}+, \mathbf{K}+, \mathrm{C} 1$-, $\mathrm{HCO} 3-, \mathrm{Ca}++, \mathrm{PO} 4=$, glucose, blood urea nitrogen, creatinine, alanine aminotransferase (ALT), aspartate aminotransferase (AST), alkaline phosphatase, lactic dehydrogenase (LDH), creatine phosphokinase (CPK), bilirubin, albumin, total protein, cholesterol, triglycerides and uric acid; routine urinalysis with microscopic examination of the sediment; and complete blood count (hemoglobin, hematocrit, and erythrocyte, leukocyte, platelet, and differential leukocyte counts). Electrocardiograms (ECG) were performed on admission and daily during therapy.

Lesion aspirate cultures were obtained 2 days after completion of therapy. Patients were asked to return 1, 3, 6 and 12 months after apparent cure, at which time an interval history, physical examination, and lesion aspiration for culture were obtained.

\section{RESULTS}

Clinical Histories: During 1977-1982 we diagnosed American cutaneous leishmaniasis in 60 patients. The mean age of the patients was 24 (range 2-41) years, and 57 of the 60 were men in active military service. The ethnic background and details of exposure are given in Table 1. Ten of the patients were diagnosed during a prospective study of an Army battalion participating in jungle warfare training at Fort Sherman in Panama 28. Two patients acquired their disease in Brazil and presented themselves to the medical field team evaluating the battalion from Panama. The remaining 48 patients presented themselves or were referred to the Walter Reed Army Medical Center with documented or suspected cutaneous leishmaniasis.

Among 35 patients with a 3 week exposure to infection in Panama, the maximum possible incubation period ranged from 4 to 81 days, with a mean of 33 days. Ten of these 35 patients developed their first lesion during the period of exposure (mean of 13 days after arrival). The other 25 developed a lesion 2 to 60 days after leaving the endemic area (mean of 42 days after first exposure and 21 days after last exposure).
Table 1 - Demographic and epidemiologic data on 60 patients with American cutaneous leishmaniasis.

\begin{tabular}{lr}
\multicolumn{2}{c}{ Ethnic background } \\
White & 37 \\
Black & 14 \\
Hispanic & 9 \\
\multicolumn{2}{c}{ Country of Exposure } \\
Panama & 55 \\
Brazil & 4 \\
Colombia & 1
\end{tabular}

$\begin{array}{lr}\text { Duration of Exposure } \\ 2 \text { weeks } & 1 \\ \text { 3 weeks } & 35 \\ 2-9 \text { months } & 7 \\ \text { 1-4 years } & 16 \\ \text { 22 years } & 1\end{array}$

One Panamanian patient developed a cutaneous lesion caused by $L$. mexicana amazonensis seven months after leaving her native country; the onset of her disease coincided with the beginning of pregnancy.

Clinical Features: Most patients had no symptoms other than awareness of their skin lesions. However, the lesions were pruritic in 19 and painful in eight. While the patients usually had a single or a few lesions located on the exposed body surfaces, $10 \%$ of them had more than five lesions (Table 2). A few patients had multiple clustered lesions, suggesting repeated probing by an infected sand fly ${ }^{6}$. Lesions varied in size from 0.2 to $6.5 \mathrm{~cm}$ maximum diameter (Table 3).

The most common type of lesion, seen in 44 patients, was an ulcer which often had elevated, indurated margins (Table 2; Figs. 1, 2).The center of the ulcer was often purulent, but occasionally it was heavily crusted. Satellite lesions around a central ulcer were seen in 15 patients. Small papular lesions were also common and occurred in 11 patients (Fig. 3). Squamous lesions (Fig. 4) were seen in three patients, an exophytic, verrucous lesion in one (Fig. 5), and acneiform lesions in one (Fig. 6). One patient developed a leishmanial ulcer at the site of an old surgical scar.

Sixteen patients had subcutaneous nodules proximal to an ulcerative skin lesion, occasionally with multiple nodules in a linear distribution. One patient with two ulcers on his arm developed a third ulcer where a subcutaneous nodule had been biopsied. Regional lymphadenopathy was present in 20 patients, and 10 of these also had subcutaneous nodules. 
Chulay JD, Oster CN, McGreevy PB, Hendricks LD, Kreutzer RD. American cutaneous leishmaniasis: presentation and problems of patient management. Revista da Sociedade Brasileira de Medicina Tropical 21: 165-172, Out-Dez, 1988

Diagnosis: There was a long delay (mean 93 days) between the onset of disease and confirmation of the diagnosis. For 51 patients, data were available to assess the factors responsible for this delay. There was a mean interval of 31 days (range 0-365 days) between appearance of a skin lesion and medical consultation, of 45 days (range 0-425 days) between medical consultation and initial consideration of cutaneous leishmaniasis, and of 17 days (range 2-120 days) until laboratory confirmation of the disease.

Twenty-three of the 60 patients were referred to us after the diagnosis had been established by finding

Table 2 - Number, location and type of lesions in 60 patients with American cutaneous leishmaniasis.

$\begin{array}{cc}\text { No. of lesions } & \text { No. of patients } \\ 1 & 26 \\ 2 & 14 \\ 3 & 7 \\ 4-5 & 7 \\ 6-10 & 4 \\ >10 & 2\end{array}$

\section{Location of lesions}

Arm

Hand or wrist

18

Leg

Face or neck

Trunk

\section{Type of lesion}

Ulcerated

Papular

Squamous

Verrucous

Acneiform amastigotes in histologic sections of skin biopsies. In another 35 patients the diagnosis of leishmaniasis was first confirmed by finding promastigotes in cultures from lesion aspirates (32), lesion biopsies (2), and a lymph node biopsy (1). The final two patients were diagnosed on the basis of exposure history, clinical appearance, and a positive serological test (one had a direct agglutination titer of 4096 and the other had an IFA titer of 32).

Overall, cultures of lesion aspirates were positive in $44 / 60(73 \%$ ) patients (including 12 of the 23 first

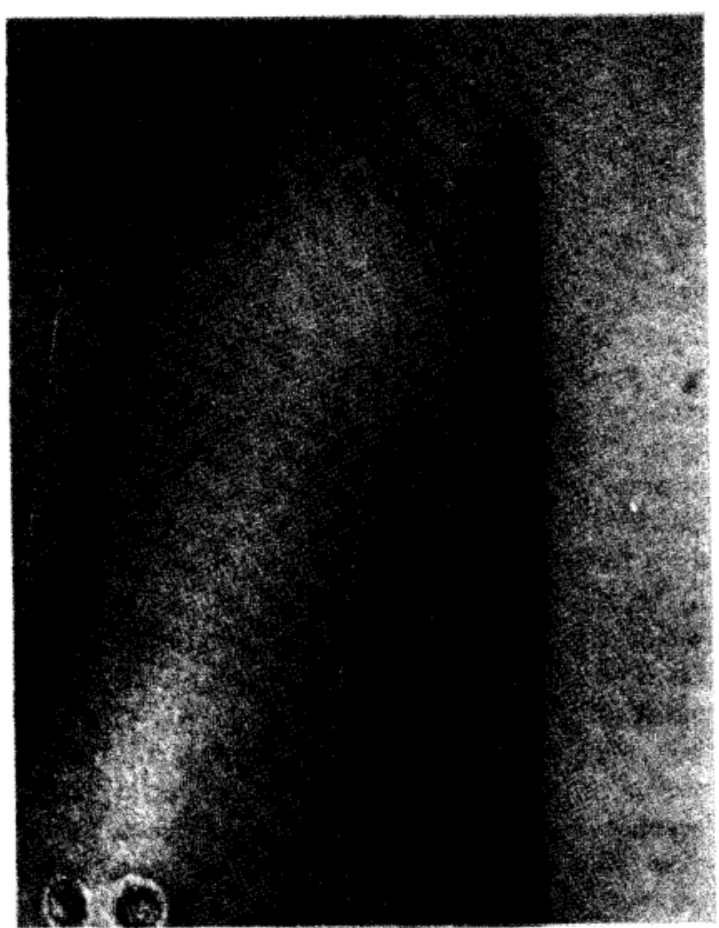

Figure 2 - Multiple ulcers of cutaneous leishmaniasis.

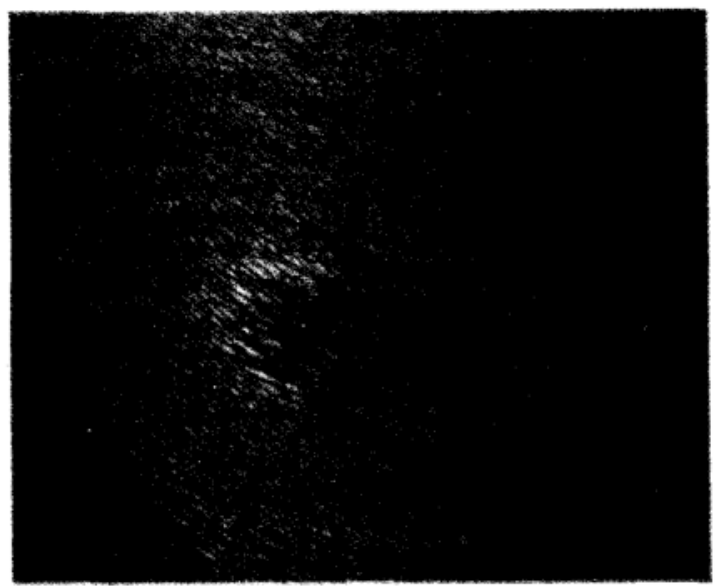

Figure $3-A 4 \times 8 \mathrm{~mm}$ papule in a case of Leishmania mexicana infection.
Figure $1-A 28 \times 35 \mathrm{~mm}$ ulcer in a case of Leishmania braziliensis panamanensis infection. 
Chulay JD, Oster CN, McGreevy PB, Hendricks LD, Kreutzer RD. American cutaneous leishmaniasis: presentation and problems of patient management. Revista da Sociedade Brasileira de Medicina Tropical 21: 165-172, Out-Dez, 1988

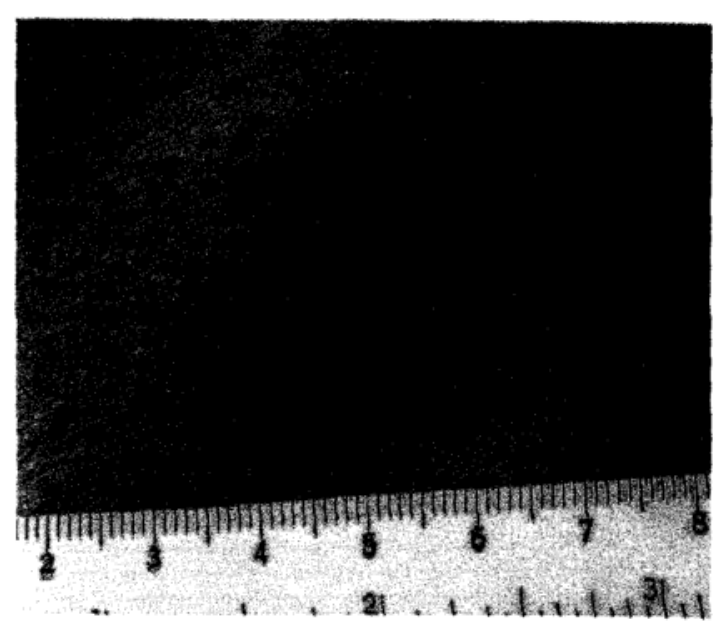

Figure 4 - A $30 \times 40 \mathrm{~mm}$ squamous lesion from which Leishmania were cultured.

diagnosed histologically). The initial aspirate culture was positive in 37 of these 44 , while six patients required two cultures and one required four cultures before organisms were isolated. Isolates from 28 patients grew sufficiently for isoenzyme analysis. Leishmania braziliensis panamensis was isolated from 13 patients, L. braziliensis braziliensis from 1 , L. mexicana amazonensis from $9, L$. mexicana mexicana from $1, L$. donovani chagasi from 3 , and a Leishmania species with an unknown isoenzyme pattern.

The isolation of $L$. d. chagasi from three patients with cutaneous lesions is of special interest because it is usually a viscerotropic species. One of these patients had a single small $(13 \mathrm{~mm})$ ulcer and another had five ulcers, including a verrucose lesion on the cheek (Fig. 5). The third patient had organisms cultured from a variety of lesions, including small papules on each elbow, excoriated papules on his thighs, an excoriation on his shoulder, and pustular acneiform lesions on his neck (Fig. 6). Because of the unusual appearance of these lesions, repeated cultures were obtained. All of six lesion cultures were positive, while two control cultures inoculated with the normal saline used to obtain aspirate cultures were negative. None of these patients had evidence of visceral leishmaniasis.

The isolation of L. m. amazonensis from simple cutaneous lesions was also interesting because this species is rarely found in man (18). Eight of these patients had papular lesions (one lesion in four and two, three or more than 10 lesions in one each) with a mean maximum diameter of $13+/-8 \mathrm{~mm}$. The other patient had a small $(5 \mathrm{~mm})$ ulcer. None of these patients had evidence of diffuse cutaneous leishmaniasis.

Thirty-one patients had portions of skin biops-

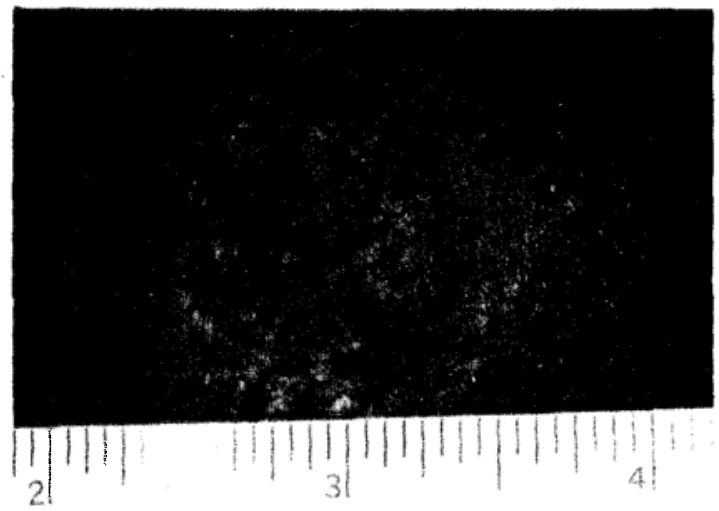

Figure 5 - A $24 \times 29 \mathrm{~mm}$ verrucous lesion of cutaneous leishmaniasis on the cheek.

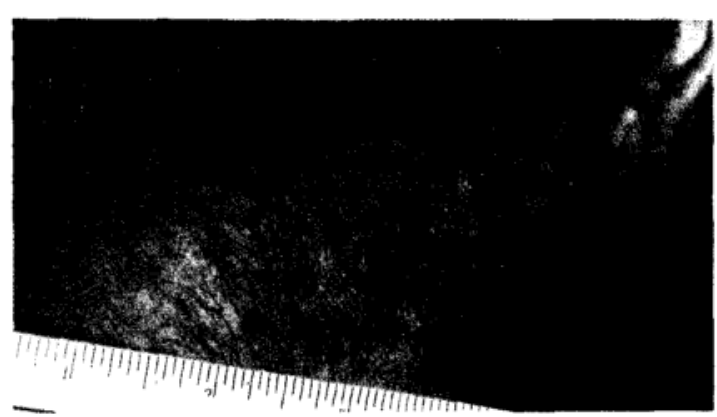

Figure 6 - Acneiform lesions on the neck from which Leishmania donovani chagasi was cultured.

ies cultured for Leishmania, and 12 (39\%) were positive. Leishmania were cultured from lymph node aspirates or biopsies in three patients.

IFA tests for leishmanial antibodies were positive in serum from $36(82 \%)$ of the 44 patients tested. The titers ranged from 8 to 64 (geometric mean titer $=16$ ).

Many patients were diagnosed early in the course of their disease because of our increased awareness of cutaneous leishmaniasis. Among the 12 patients who were diagnosed in connection with the prospective study during jungle warfare training, nine had small papular or squamous lesions not usually considered suggestive of leishmaniasis, and the lesions of five of these had improved spontaneously prior to diagnosis. Isolates from 7 of these papular lesions were identified as $L$. mexicana (L. m. amazonensis in six and L.m. mexicana in one). Another patient diagnosed early in his illness was an Army parasitologist studying leishmania in his laboratory who developed a small, culture-positive papule on his thumb caused by $L$. $m$. amazonensis. The individual with excoriated papular and acneiform lesions was cultured only because he had resided in Panama for 2 years. 
Chulay JD, Oster CN, McGreevy PB, Hendricks LD, Kreutzer RD. American cutaneous leishmaniasis: presentation and problems of patient management. Revista da Sociedade Brasileira de Medicina Tropical 21: 165-172, Out-Dez, 1988

Treatment. Fifty-six patients, including 36 who participated in a prospective randomized clinical trial (22), were treated with sodium stibogluconate intravenously (54 patients) or intramuscularly ( 2 patients). Only $32(57 \%)$ were cured (healed lesions and negative aspiration cultures) after a single 10 day course of treatment. Sixteen patients required a second, two a third, and one a fourth 10 day course of sodium stibogluconate to achieve clinical and parasitological cure.

The clinical response to sodium stibogluconate treatment was usually prompt. Within 7 to 10 days after starting treatment, all patients showed signs of healing (reduced drainage and crusting, less induration of the lesion margin, and epithelialization of the ulcer base). However, 24 patients required additional therapy because of the persistance of the lesions or the relapse of healed lesions (11 patients), a positive culture (3), or both a positive culture and persistent lesions (10). Complete healing often required several months.

Five patients were not cured after multiple 10 day courses of sodium stibogluconate. One of these patients had healing of his lesions after treatment with trimethoprim sulfamethoxazole. In a second patient, ulcers on his arm healed after three courses of sodium stibogluconate but he had recurrent, nonulcerating subcutaneous nodules. Repeated cultures of the nodules were negative, and he was not given additional therapy. Three of these antimony failures were treated with amphotericin B, but none had a favorable response. The first had persistent positive cultures despite clinical healing of his lesions after three courses of sodium stibogluconate and treatment with amphotericin (which was limited to $0.28 \mathrm{gm}$ total dose because of rapid onset of azotemia). The second and third patients received larger doses of amphotericin (1.0 and 2.9 $\mathrm{gm})$. Their shallow ulcers healed slowly after the end of treatment, but recurred intermittently for more than 2 years.

Meglumine antimonate was given intramuscularly to three patients. Two achieved clinical and parasitological cure. The third healed clinically, but remained culture positive. His cultures became negative after retreatment with one course of sodium stibogluconate.

Twenty-five patients were seen at least 9 months after completion of treatment. Twenty-one of these remained clinically and parasitologically cured. Four patients had clinically healed lesions eventhough parasites were cultured from the lesion site on at least one occasion after treatment; lesions in all four remained healed without further treatment. Among the 18 patients followed for 2-8 months, 17 appeared cured and one had mild clinically active disease despite negative cultures. Sixteen patients who ap- peared cured at discharge 2 weeks after completing therapy failed to return for follow-up examination. Six of these patients responded to a mailed questionaire, and each denied any activity of his disease since treatment. One patient had spontaneous healing without therapy.

We identified three factors which appeared to influence prognosis: lesion type, lesion size, and the species of Leishmania causing the infection. Ulcerated lesions were less likely to be cured after a single course of treatment than were nonulcerated lesions $\left(19 / 43\right.$ vs $\left.15 / 16, x^{2}=11.73, p<0.001\right)$. Large lesions were less likely to be cured after a single course of treatment than were small lesions (Table 3 ). Lesions caused by $L$. braziliensis were less likely to be cured after a single course of treatment than were lesions caused by other species ( $4 / 14$ vs $12 / 14, x^{2}=9.33$. $p<$ 0.005 ). However, these three factors are interrelated, because lesions caused by $L$. braziliensis were larger (diameter $34+/-13 \mathrm{~mm}$ ) than those caused by other species (diameter $16+/-10 \mathrm{~mm} . \mathrm{p}<0.001$. Student's t-test), and lesions caused by $L$. mexicana were less likely to ulcerate $(1 / 10)$ than those caused by' $L$. donovani chagasi $(2 / 3)$ or $L$. braziliensis $(14 / 14)$ $\left(\mathrm{x}^{2}=20.28,2 \mathrm{df}, \mathrm{p}>0.001\right)$.

The duration of infection did not appear to influence either the type or size of the lesions or the response to treatment. The median duration of infection before treatment was 106 days for ulcerative lesions and 105 days for papular lesions; 107 days for lesions $<2 \mathrm{~cm}$ in diameter and 111 days for lesions $>2$ $\mathrm{cm}$ : and 111 days for lesions which where cured after

Table 3-Relationship between size of lesion and clinical response to initial treatment with pentavalent antimonial drugs in 59 patients with American cutaneous leishmaniasis.*

\begin{tabular}{rcc}
\hline $\begin{array}{c}\text { Diameter } \\
\text { of largest } \\
\text { lesion (cm) }\end{array}$ & $\begin{array}{c}\text { Number of } \\
\text { patients } \\
\text { treated }\end{array}$ & $\begin{array}{c}\text { Number of patients } \\
\text { cured with initial } \\
\text { treatment course (\%) }\end{array}$ \\
$<1.0$ & 6 & $5(83)$ \\
$1.0-1.9$ & 14 & $10(71)$ \\
$2.0-2.9$ & 12 & $6(50)$ \\
$3.0-3.9$ & 14 & $6(43)$ \\
$>4.0$ & 13 & $7(53)$ \\
Total & 59 & $34(58)$ \\
\hline
\end{tabular}

* Cure rate for lesions $<2 \mathrm{~cm}$ diameter tended to be better than for lesions $>2 \mathrm{~cm}\left(75 \%\right.$ vs $46 \%, x^{2}=3.74$, $\mathrm{p}<0.06)$. 
one course of treatment and 106 days for lesions requiring more than one treatment course.

Side Effects: Treatment with antimonials did not produce serious side effects. All five patients who received intramuscular therapy complained of pain at the injection site. Other symptoms possibly related to sodium stibogluconate treatment developed in 13 patients. These included headache ( 8 patients), blurred vision ( 3 patients), and mild abdominal pain, diarrhea, pruritic rash, tinnitus, myalgias, anorexia, depression and palpitations ( 1 each). Twenty-one patients developed objective clinical or laboratory abnormalities during treatment. Four developed superficial thrombophlebitis at the site of infusion and one developed a painful, indurated, violaceous lesion at an infiltrated intravenous injection site. Transient elevations of serum ALT, LDH or AST occurred in eight, four and three patients, respectively. Transient elevations of serum triglycerides, CPK, or alkaline phosphatase occurred in three, two and one patient, respectively. Three patients had nonspecific ST and T wave changes on ECG. One young man had an intermittent low atrial pacemaker during treatment. This was considered to be a normal variant ${ }^{14}$ and unrelated to the sodium stibogluconate therapy. Thirty-five patients had no side effects from treatment.

\section{DISCUSSION}

Our patients with American cutaneous leishmaniasis presented with a variety of skin lesions. Although ulcerated lesions were most common, 27\% of the patients had atypical papular, macular, squamous, verrucous or acneiform lesions which were diagnosed because of a high index of suspicion and the ability to obtain leishmanial cultures. Cutaneous leishmaniasis should be considered in the differential diagnosis of any chronic skin lesion in a patient who has spent time in an endemic area. In the Americas these areas include parts of Texas and every country south of the United States, with the exception of Uruguay. The incubation period for 35 soldiers who had a brief exposure to infection in Panama was always less than 90 days; therefore, leishmaniasis should be strongly considered when chronic skin lesions develop during residence in an endemic area, or within 3 months of leaving the area. Infrequently, skin lesions due to leishmaniasis may appear later, as in the patient who developed her first lesion 7 months after arriving in the U.S. Consequently, a prolonged incubation period should not be used as grounds to exclude the possibility of leishmaniasis.

After experimental infections with $L$. tropica in man, only $50 \%$ of lesions ulcerate; the rest become papular, often with scaling, and then heal spontaneously $^{26}$. Our experience with 10 patients diagnosed in conjunction with a prospective study during jungle warfare training suggests that spontaneous healing, often without progression to ulceration, can also occur in American cutaneous leishmaniasis caused by L. m. amazonensis. This is in sharp contrast to persistant diffuse cutaneous leishmaniasis and mucosal leishmaniasis caused by L. m. amazonensis. 1824

The diagnosis of cutaneous leishmaniasis was delayed an average of 3 months in our patients due to three factors: patient delay in seeking medical advice, physician delay in considering the diagnosis, and laboratory delay in confirming the diagnosis. The first two factors might be addressed by educating people at risk and the physicians likely to provide them health care.

Confirming the diagnosis of cutaneous leishmaniasis is often difficult. Serogical tests are non-specific ${ }^{23}$ and relatively insensitive ${ }^{131}$, especially early in the course of disease 28 . Moreover, they are available at only a few reference laboratories. Histopathologic changes are said to be highly suggestive of the correct diagnosis ${ }^{30}$ but, in our experience, histopathology often revealed only non-specific inflammatory changes without identifying the causative organism 28 . The Montenegro skin test has not been standardized or adequately evaluated and it is not generally available. Antigen preparations vary among investigators. A number of publications indicate that the sensitivity of these preparations is $>80 \%$, but there is only meagre data on their specificity and cross-reactivity. Slit skin smears that are performed the same way as in cases of suspected leprosy and stained with Giemsa may demonstrate amastigotes, but they are often negative in infections caused by L. braziliensis. Culturing tissues from lesion aspirates and biopsies in appropriate media at room temperature allows conversion of amastigotes into promastigotes which subsequently multiply. Performed carefully, cultures are the most sensitive and practical method currently available to establish the diagnosis 33 . Various culture media have been used for this purpose 132733 , but none is universally successful 9 . There is a need for new diagnostic methods that are more sensitive and rapid. The recent development of Leishmania subspecies-specific monoclonal antibodies 2122 and kinetoplast DNA probes 5 hold forth the promise of rapid, definitive diagnosis by visualizing amastigotes in diseased tissue by fluorescent microscopy or DNA hybridization techniques $^{3} 5$.

The management of cutaneous leishmaniasis is often difficult because of the varied natural history of the disease and the suboptimal response to current treatment regimens. Skin lesions are usually selflimited, but they often require 6-18 months to heal spontaneously 30 and may cause considerable cosmetic disfigurement. Mucosal disease occurs rarely after 
Chulay JD, Oster CN, McGreevy PB, Hendricks LD, Kreutzer RD. American cutaneous leishmaniasis: presentation and problems of patient management. Revista da Sociedade Brasileira de Medicina Tropical 21: 165-172, Out-Dez, 1988

cutaneous infection with $L$. b. panamensis. However, $3 \%$ of patients with simple cutaneous leishmaniasis caused by $L$. b. braziliensis develop mucosal disease from months to years after an inapparent or self-healing infection 192532 . Treatment with pentavalent antimonial drugs appears to shorten the time required for healing of skin lesions 1530 . Our experience supports this impression as clinically active lesions improved within 10 days of starting therapy in all of our patients. Although data are limited, it is likely that systemic treatment with antimonial drugs also decreases the risk of late mucosal disease ${ }^{19}$. For these reasons, we recommend treatment for all patients with active lesions, and for patients with confirmed or presumed $L$. braziliensis infections, even if their lesions have healed spontaneously.

Forty-two percent of the patients we treated required more than one course of therapy, and $9 \%$ were not cured after multiple courses of pentavalent antimonial drugs. It is likely that the dose in conventional treatment regimens of sodium stibogluconate is too small and the duration of treatment too short. The levels of sodium stibogluconate required to inhibit Leishmania in vitro are frequently equal to or higher than the peak blood concentration after standard therapy with $600 \mathrm{mg} \mathrm{Sb}{ }^{7}$. Due to rapid urinary excretion these peak blood levels are maintained for only a brief period of time ${ }^{12}$. Studies of visceral and cutaneous leishmaniasis in Kenya and India have demonstrated increased efficacy without serious toxicity when higher daily doses of sodium stibogluconate were used for up to 40 days 2101129 . Based on this information, we recently conducted a controlled trial in 40 patients with cutaneous ulcerative lesions caused by $L$. braziliensis panamensis in which we compared treatment with sodium stibogluconate at 10 and $20 \mathrm{mg}$ $\mathrm{Sb} / \mathrm{kg}$ daily for 20 days. The lower dose cured only $76 \%$ of 21 patients, but the higher dose cured all of 19 patients ${ }^{4}$. Because the prognosis of American cutaneous leishmaniasis is influenced by the type and size of the lesion as well as the species of Leishmania, similar studies on the treatment of cutaneous leishmaniasis caused by other species of Leishmania or other types of lesions would be useful.

\section{RESUMO}

Relatamos nossa experiência em 60 pacientes com leishmaniose tegumentar americana diagnosticada e tratada entre 1977 e 1982. Cinqüenta e cinco pacientes foram infectados no Panamá, 4 no Brasil, e 1 na Colômbia. Entre 35 pacientes com uma exposição de 3 semanas no Panamá, a média do período de incubação foi 33 dias (limite sobre 4 e 81 dias). $O$ diagnóstico foi feito, em média, 93 dias depois do inicio das lesōes de pele, devido a demora do paciente em procurar o serviço médico (31 dias), a demora do médico em considerar o diagnóstico (45 dias), e a demora do laboratório em confirmar o diagnóstico (17 dias). Quarenta e quatro pacientes (73\%) desenvolveram úlceras típicas de leishmaniose cutânea. Porém, 16 pacientes $(27 \%)$ tiveram lesões de pele atípicas maculares, papulares, escamosas, verrucosas ou acneiformes que foram diagnosticadas somente através de culturas de leishmania. De 59 pacientes tratados com o antimonial pentavalente, só 34 (58\%) obtiveram cura depois da primeira série de tratamento. Em pacientes com lesões maiores do que $2 \mathrm{~cm}$ de diâmetro, ou causada por Leishmania braziliensis, ocorrem menos indice de cura depois da primeira série de tratamento do que naqueles com lesões menores do que $2 \mathrm{~cm}$, fechadas, ou causadas por $L$. mexicana ou L. donovani.

Palavras-chaves: Leishmaniose tegumentar americana. Diagnóstico. Tratamento. Prognóstico. Patologia Clinica.

\section{ACKNOWLEDGEMENTS}

We thank B. Stoltman, N. Wright, J. Andujar, E. Jenkins, and A. Wolf for assistance in culturing and typing Leishmania, and M. Pappas and R. Hajkowski for performing the IFA tests.

The views of the authors do not purport to reflect the position of the Department of the Army or the Department of Defense, USA.

\section{REFERENCES}

1. Allain DS, Kagan IG. A direct agglutination test for leishmaniasis. American Journal of Tropical Medicine and Hygiene 24: 232-236, 1975.

2. Anabwani GM, Ngira JA, Dimiti G, Bryceson ADM. Comparison of two dosage schedules of sodium stibogluconate in the treatment of visceral leishmaniasis in Kenya. Lancet I: 210-212, 1983.

3. Anthony RL, Grogl M, Sacci JB, Ballou RW. Rapid detection of Leishmania amastigotes in fluid aspirates and biopsies of human tissues. American Journal of Tropical Medicine and Hygiene 37: 271-276, 1987.

4. Ballou WR,McClain JB, Gordon DM, Shanks GD, Andujar J, Berman JD, Chulay JD. Safety and efficacy of high-dose sodium stibogluconate therapy of American cutaneous leishmaniasis. Lancet II: 13-16, 1987.

5. Barker DC. DNA diagnosis of human leishmaniasis. Parasitology Today 3: 177-184, 1987.

6. Beach R, Kiilu G, Hendricks L, Oster C, Leeuwenburg J. Cutaneous leishmaniasis in Kenya: transmission of Leishmania major to man by the bite of a naturally infected Phlebotomus duboscqi. Transactions of the Royal Society of Tropical Medicine and Hygiene 78: 747-751, 1984. 
Chulay JD, Oster CN, McGreevy PB, Hendricks LD, Kreutzer RD. American cutaneous leishmaniasis: presentation ana problems of patient management. Revista da Sociedade Brasileira de Medicina Tropical.21: 165-172, Out-Dez, 1988

7. Berman JD, Chulay JD, Hendricks LD, Oster CN. Susceptibility of clinically sensitive and resistant Leishmania to pentavalent antimony in vitro. American Journal of Tropical Medicine and Hygiene 31: 459-465, 1982.

8. Burroughs Wellcome Co. Pentostam package insert. 1976.

9. Chaves F, Silva S, Zeledon R. Comparison of two culture media for the isolation of Leishmania strains. Journal of Parasitology 68: 346-347, 1982.

10. Chulay JD, Anzeze EM, Koech DK, Bryceson AD. High-dose sodium stibogluconate treatment of cutaneous leishmaniasis in Kenya. Transactions of the Royal Society of Tropical Medicine and Hygiene 77: 717-721, 1983.

11. Chulay JD, Bhatt SM, Muigai R, HoM, Gachihi,G, Were JB, Chunge $C$, Bryceson AD. A comparison of three dosage regimens of sodium stibogluconate in the treatment of visceral leishmaniasis in Kenya. Journal of Infectious Diseases 148: 148-155, 1983.

12. Chulay JD, Fleckenstein L, Smith DH. Pharmacokinetics of antimony during treatment of visceral leishmaniasis with sodium stibogluconate or meglumine antimoniate. Transactions of the Royal Society of Tropical Medicine and Hygiene 82: 69-72, 1988.

13. Hendricks LD, Wright N. Diagnosis of cutaneous leishmaniasis by in vitro cultivation of saline aspirates in Schneider's Drosophila Medium. American Journal of Tropical Medicine and Hygiene 28: 962-964, 1979.

14. Hiss RG, Lamb LE. Electrocardiographic findings in 122, 043 individuals. Circulation 25: 947-961, 1962.

15. Kern F, Pedersen JK. Leishmaniasis in the United States. A report of ten cases in military personnel. Journal of the American Medical Association 226: 872-874, 1973.

16. Kreutzer RD, Semko ME, Hendricks LD, Wright $\mathbf{N}$. Identification of Leishmania spp. by multiple isozyme analysis. American Journal of Tropical Medicine and Hygiene 32: 703-715, 1983.

17. Kreutzer RD, Souraty N, Semko ME. Biochemical identities and differences among Leishmania species and subspecies. American Journal of Tropical Medicine and Hygiene 36: 22-32, 1987.

18. Lainson R. The American leishmaniases: some observations on their ecology and epidemiology. Transactions of the Royal Society of Tropical Medicine and Hygiene 77 : 569-596, 1983.

19. Marsden PD, Llanos-Cuentos EA, Lago EL, Cuba CC, Barreto AC, Costa JM, Jones TC. Human mucocutaneous leishmaniasis in Tres Braços, Bahia - Brazil. An area of Leishmania braziliensis braziliensis transmission. III. Mucosal disease presentation and initial evolution. Revista da Sociedade Brasileira de Medicina Tropical 17: 179-186, 1984.

20. McMahon-Pratt D, Bennett E, David JR. Monoclonal antibodies that distinguish subspecies of Leishmania braziliensis. Journal of Immunology 129: 926-927, 1982.

21. McMahon-Pratt D, Bennett E, Grimaldi G, Jaffe CL. Subspecies - and species-specific antigens of Leishma nia mexicana characterized by monoclonal antibodies. Journal of Immunology 134: 1935-1940, 1985.

22. Oster CN, Chulay JD, Hendricks LD, Pamplin III CL, Ballou WR, Berman JD, Takafuji ET, Tramont EC, Canfield CJ. American cutaneous leishmaniasis: a comparison of three sodium stibogluconate treatment schedules. American Joumal of Tropical Medicine and Hygiene 34: 856-860, 1985.

23. Pappas MG, McGreevy PB, Hajkowski R, Hendricks LD, Oster CN, Hockmeyer WT. Evaluation of promastigote and amastigote antigens in the indirect fluorescent antibody test for American cutaneous leishmaniasis. American Journal of Tropical Medicine and Hygiene 32: 1260-1267, 1983.

24. Sampaio RN, Marsden PD, Llanos Cuentas EA, Cuba CAC, Grimaldi G. Leishmania mexicana amazonensis isolated from a patient with fatal mucosal leishmaniasis. Revista da Sociedade Brasileira de Medicina Tropical 18: 273-274, 1985.

25. Saravia NG, Holguin AF, McMahon-Pratt D, D'Alessandro A. Mucocutaneous leishmanisis in Colombia: Leishmania braziliensis subspecies diversity. American Journal of Tropical Medicine and Hygiene 34: 714-720, 1985.

26. Senekji HA, Beattie CP. Artificial infection and immunization of man with cultures of Leishmania tropica. Transactions of the Royal Society of Tropical Medicine and Hygiene 34: 415-419, 1941.

27. Shaw JJ, Lainson $R$. The in vitro cultivation of members of the Leishmania braziliensis complex. Transactions of the Royal Society of Tropical Medicine and Hygiene 75: 127, 1981 .

28. Takafuji ET, Hendricks LD, Daubek JL, McNeil KM, Scagliola HM, Diggs CL. Cutaneous leishmaniasis associated with jungle training. American Journal of Tropical Medicine and Hygiene 29: 516-520, 1980.

29. Thakur CP, Kumar M, Kumar P, Mishra BN, Pandey AK. Rationalisation of regimens of treatment of Kala-azar with sodium stibogluconate in India: a randomised study. British Medical Journal 296: 1557-1561, 1988.

30. Thomburgh DB, Johnson CM, Elton NW. Histopathology of cutaneous leishmaniasis in Panama. Transactions of the Royal Society of Tropical Medicine and Hygiene 46: 550-554, 1952.

31. Walton BC, Brooks WH, Arjona I. Serodiagnosis of American leishmaniasis by indirect fluorescent antibody test. American Journal of Tropical Medicine and Hygiene 21:296-299, 1972.

32. Walton BC, Chinel LV, Eguia OE. Onset of espundia after many years of occult infection with Leishmania braziliensis. American Joumal of Tropical Medicine and Hygiene 22: 696-698, 1973.

33. Weigle KA, de Dávalos M, Heredia P, Molineros $R$, Saravia NG, D'Alessandro A. Diagnosis of cutaneous and mucocutaneous leishmaniasis in Colombia: A comparison of seven methods. American Journal of Tropical Medicine and Hygiene 36: 489-496, 1987. 